\title{
Quality Characteristics of an LMS UX Psychomotor Model for the Design and Evaluation of Learning Management Systems
}

\author{
Emmanuel O.C. Mkpojiogu ${ }^{1,2, *}$, Obianuju E. Okeke-Uzodike ${ }^{3}$, Emelda I. Emmanuel ${ }^{4}$ \\ ${ }^{1}$ School of Computing, Universiti Utara Malaysia, 06010 UUM, Sintok, Malaysia \\ ${ }^{2}$ Department of Computer and Information Technology, Veritas University, Abuja, Nigeria \\ ${ }^{3}$ Faculty of Management Sciences, Department of Applied Management, Durban University of Technology, Riverside \\ Campus, Pietermaritzburg KwaZulu-Natal, South Africa. \\ ${ }^{4}$ Department of Sociology, Ibrahim Babamasi Babangida University, Lapai, Nigeria. \\ *Corresponding author. Email: emelnuel@hotmail.com
}

\begin{abstract}
In this study an investigation was conducted to ascertain the possibility of conceptualizing and developing a native user experience psychomotor model for the design and evaluation of the experiences of learning management systems (LMSs) users. The paper found that no previous model of this kind is in existence. Sequel to this discovery, a conceptualization of the model was done using the psychomotor component of the Bloom's learning taxonomy. The study then captured suitable dimensions/quality elements that best define/influence the model. These dimensions and quality elements include interactivity, engageability, ludicity, and sociability. The study hence proposes the adoption of this novel UX psychomotor model for the design and evaluation of the user experiences of LMS platforms learners.
\end{abstract}

Keywords: Learning management systems, LMS UX psychomotor model, Quality characteristics, User experience.

\section{BACKGROUND}

With the rapidity in the growth of the Internet, the teaching and learning domains have been transformed from a conventional classroom platform to an electronic or mobile platform. Several learning management systems (LMSs) such as Edmodo, Moodle and Blackboard Apps among others [1-4] are used to support virtual learning. These applications aid teachers to provide teaching materials to students; carry out webbased tests and deliver assignments to students. Students on the other hand can download and learn with these materials anytime, anywhere [5]. Ann [6] reported that by 2022 , the size of online learning industry will amount to 243 billion USD with a compound growth rate of $5 \%$ annually from 2017 to 2022 . LMS overcomes the space and time constraints that constrain learning.

The understanding of user experience (UX) is a first step to the user-centered design approach [7-12] for the development of educational applications to be assessed by a teeming number of thousands of students irrespective of place and time. The UX research community has conducted research in a number of domains and contexts of interaction like interactive entertainment system [13]; social media [14]; industrial environment and systems [15]; interactive environments [16]; interactive kiosks systems [17]; interactive products [18]; mobile applications [19]; healthcare systems [20]; augmented reality apps [21]; and e-commerce websites [22]. However, in the context of teaching and learning, UX is relatively new [5]. The ubiquitous access to the Internet has aided virtual education. Students no longer need to be physically present at the same time and place where the teacher is [5]. This has enhanced the development of virtual learning applications. The learning experience (LX) in virtual learning systems can be classified into asynchronous and synchronous (i.e., real time) [23]. Asynchronous is the process which occurs when the learning experience is accomplished offline while conversely, synchronous learning is the process that happens when the learning experience is attained real time as it enables students to interact directly 
and collaborate with their teachers and peers through the learning applications/platforms [24]. While the asynchronous approach supports fewer interactions than the synchronous learning, its main advantage however results from the increased personalized learning experience [25] and it increases the information retention of students by tailoring the learning process to the students' time, pace and place [5]. It also enables learners to interact and engage with learning contents more. Despite the many research done in user experience [26$30]$ in the context of virtual learning, no study has been reported on user experience for interactive virtual learning generally and psychomotor learning experience particularly [5], thus, the need for a study in this domain.

In this study, the user experience psychomotor model for the design and evaluation of the UX of LMS platforms was conceived and developed from the psychomotor component of Bloom learning taxonomy [31]. Bloom noted that the psychomotor domain of the model takes into account subdomains of perception, set, guided response, mechanism, complex over response, adaptation, and origination. The psychomotor model explains the stimulating effects of learning stimuli on the psychological being of users as they physically participate in learning activities. For Aheisibwe et al. [54], the psychomotor domain is action-based and entails developing or acquiring changes in behaviour or skills. The users' psychomotor organism affected by design factors (stimuli) relates to sensory related activities which in turn lead to experiential responses from users/learners that define their psychomotor experience [32]. The design of an LMS can trigger certain engagement from learners that makes them to be more involved in the learning process. Users/learners' psychomotor is associated with experiences that come as an outcome of some sensory cum bodily interactions in terms of verbal, visual or haptic/tactile. It connects to learning tied to an authentic activity. This scenario is supported by the situated cognition theory which views learning and doing as interwoven activities [33-34]. This model is also supported by the self-determination theory and selfefficacy theory which indicate how LMS can support learners to be responsible for their learning activities and be able to learn independently without external assistance within a relational social learning context and ecosystem [35]. Psychomotor is a behavioral model and its attributes mirror users/learners' immersive involvement in the learning process

The stimuli or the design factors that impact on psychomotor being of learners are: i) interactivity [3639]: the capability of the LMS to enable users' competence in and control over the interactive process influences their psychomotor perception (Guimaraes et al., 2017); ii) engageability [7] [38-41]: the level at which the LMS supports users/learners immersive engagement and absorption in the learning process makes or mars their psychomotor organismic experiences; iii) ludicity
[42]: the extent to which an LMS supports interactive playful and gamified learning has effect on the learners' psychomotor being [41]; ix) sociability [7] [43-44]: the LMS platform that supports interactivity, responsiveness, dialogism, communication and collaboration etc. amid users/learners' learning enhances the psychomotor experience of such users/learners [41] [45,48]. Evidences from prior literatures show that there are no UX psychomotor model for the design and evaluation of LMS platforms. This present study is geared to conceptualize and propose this model for experience design and evaluation purposes [55-60].

\section{METHODOLOGY}

This study employed a mapping strategy to develop a conceptual UX psychomotor model for the design and evaluation of users' experience with learning management systems [61-65]. The mapping strategy involved the review of literature to ascertain gaps in literature and the possibility of conceptualizing the model. In a nutshell, the procedure adopted in this paper is as follows (Figure 1): i) download scholarly articles relating to the modeling of the psychomotor experiences of users of learning management system platforms; ii) synthesize and analyze the downloaded articles; iii) extract useful and relevant information relating to the modeling of the psychomotor experiences of leaners using LMS platforms; iv) conceptualize and propose the UX psychomotor model for the design and evaluation of users'/learners experience on LMS platforms [66-68].

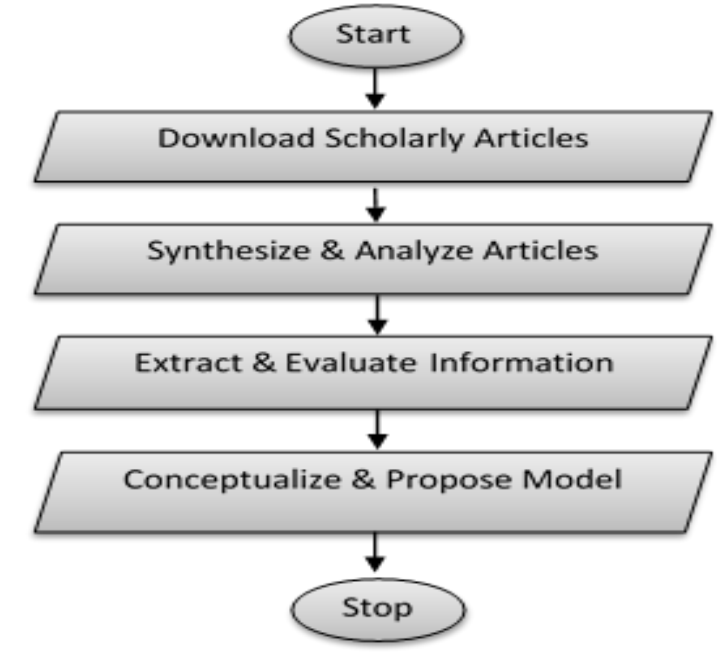

Figure 1 Study Steps

\section{RESULTS}

The findings of the study firstly reveal that no previous psychomotor model for the design and evaluation of user experience of learning management systems exits. Second, the study also unveiled the possibility of mapping the psychomotor component of the Bloom's learning taxonomy with the user experience 
psychomotor model. Third, the outcome of the study explored and discovered four dimensions/attributes that explain the psychomotor model in the context of LMS design and evaluation. Figure 2 and Table 1 explains the psychomotor model for the design and evaluation of LMS learning environments.

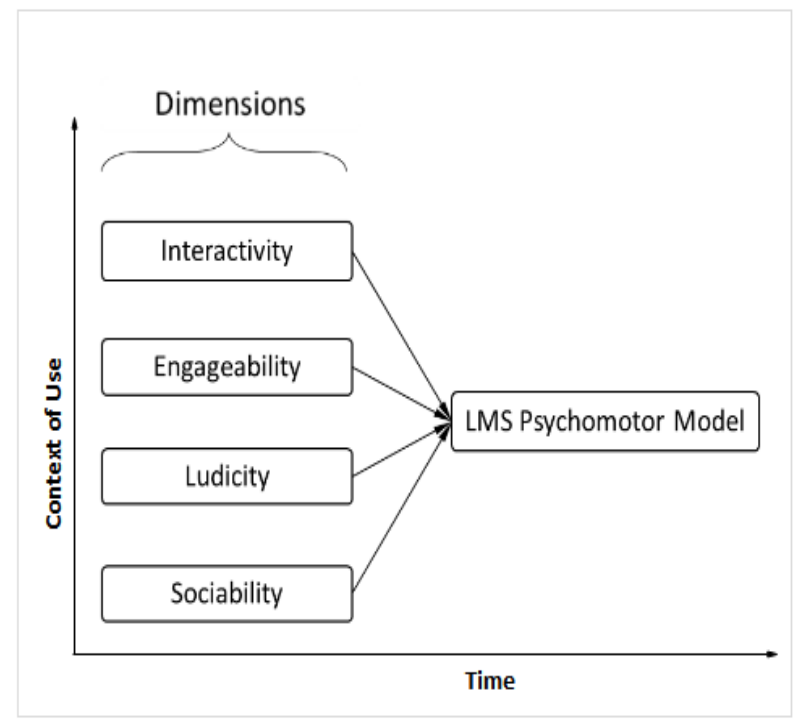

Figure 2 An LMS Psychomotor Model

Table 1. Dimensions of UX Psychomotor Model for LMS Design and Evaluation

\begin{tabular}{|l|l|}
\hline Model & Dimensions/attributes \\
\hline Psychomotor [49-50] & Interactivity [3] \\
\cline { 2 - 2 } & Engageability [4] [46] \\
\cline { 2 - 2 } & Ludicity [42] [51] \\
\cline { 2 - 2 } & Sociability [52-53] \\
\hline
\end{tabular}

The psychomotor model relates to experiences that arise in the course of learning activities as a result of learners' sensory-related bodily interactions in terms of verbal, aural, visual or haptic. It relates to learning tied to an authentic activity. This model ties learning and doing as inseparable entities and reflect users/learners' immersive involvement in learning related activities. The model can be measured as follows:

1. User Engagement: This quality explains the extent of learners' active and lively involvement in learning activities on the LMS platform. This immersive participation describes the sensorimotor/psychomotor of the LMS platform as it makes learners have the feeling of flow, telepresence, social (co-)presence, absorption, and immersion.

There are four attributes/dimensions that determine the psychomotor model. They include: i. Interactivity: This attribute entails the degree to which an LMS platform allows for interaction and how responsive it is to support learning activities. Learning can only take place when the learning platform is controllable by and responsive to the user/learner. Thus, interactivity influences the learners sensorimotor/psychomotor.

ii. Engageability: This attribute includes UX qualities that stimulate user engagement on/with the LMS platform. It deals with users feeling of being involved in and immersed with the learning platform they are interacting and learning with. It captures the level at which users/learner's attention and interest is captivated and sustained during learning interaction and the degree of sustenance of users/learners' interest during such interaction. With learners' active involvement and deep participation with learning activities, the learning process will be affected. Hence, engageability affects the sensorimotor (psychomotor) of learners on the LMS platform.

iii. Ludicity: This quality involves all forms of playful or fun activities that are geared towards stimulating or motivating learning activities. This criterion enables users/learners to lively interact with and learn on the LMS with the feeling of fun and amusement. Ludic qualities and activities influence learners' sensorimotor/ psychomotor organism.

iv. Sociability: This quality includes the factors that deal with how an LMS platform mediates between learners as these learners interact through the platform with other learners. It depicts LMS as a communal ecosystem where learners share, communicate and collaborate with each other while learning, with a socio-cultural (socio-anthropological) understanding and respect for each other. This criterion creates a learning community and fosters communication, sharing, and collaboration among learners. Sociability promotes learners' sensorimotor/ psychomotor and gives learners a feeling of co-presence in learning. It also gives them a sense of belonging, identity, friendship, love and psychological ownership. This improves the charisma of the platform. Thus, an LMS that is not sociable will affect the psychomotor/ sensorimotor of the platform. 
Following these assertions and findings, this study conceptualizes and proposes the user experience psychomotor model for the design and evaluation of the experiences of users of LMS platforms.

\section{CONCLUSION}

This study investigated the possibility of developing a custom UX psychomotor model for the design and evaluation of the experiences of LMS users. The study discovered that no prior model of this nature exits and then conceptualized the model from the psychomotor component of the Bloom's taxonomy of learning. The study also elicited appropriate dimensions/ quality attributes that contribute to the model. These dimensions and quality attributes are interactivity, engageability, ludicity, and sociability. The paper therefore proposes the adoption of this new user experience psychomotor model for the design and evaluation of the experiences of users of/learners with LMS platforms.

\section{AUTHORS' CONTRIBUTIONS}

All authors contributed to the content and quality of the article.

\section{ACKNOWLEDGMENTS}

The authors wish to acknowledge and thank the management of Durban University of Technology, Riverside Campus, Pietermaritzburg, KwaZulu-Natal, South Africa for sponsoring the research.

\section{REFERENCES}

[1] [N. Cavus, T. Zabadi. A comparison of open source learning management systems. Procedia - Social and Behavioral Sciences, 1432014 521-526.

[2] G.S.W. Joko. The development of learning management system using Edmodo. IOP Conf. Series: Materials Science and Engineering, 336 2016, IOP Publishing.

[3] T.L.A. Sucipto, A. Efendi, H.N. Hanif, C. Budiyanto. The influence of learning management technology to student's learning outcome. International Journal of Pedagogy and Teacher Education (IJPTE), 1(1) 2017 11-18.

[4] A.B. Prasetya, K. Taroreh. The implementation of socialization, externalization, combination, and internalization (SECI) through Edmodo application to improve students group's learning outcomes. Advances in Social Science, Education and Humanities Research. International Conference on Education Innovation (ICEI'17), Atlantis Press, 2018 5-8

[5] S. Jusoh, S. Almajali, A. Abualbasal. A study of user experience for e- learning using interactive online technologies. Journal of Theoretical and Applied Information Technologies, 97(15) 2019 4036-4047.

[6] M. Ann. eLearning platforms you can use for online courses. 2018 https://elearningindustry.com/elearning-platformsuse-online-courses-10.

[7] R. Kraleva, M. Sabani, V. Kralev. An analysis of some learning management systems. International Journal on Advanced Science Engineering Information Technology, 9(4) 2019 1190-1198.

[8] A. Hussain, E.O.C. Mkpojiogu, H. Almazini, H. Almazini. Assessing the usability of shazam mobile app. Proceedings of the $2^{\text {nd }}$ International Conference on Applied Science and Technology (ICAST'17), Kedah, Malaysia. AIP Conference Proceedings $1891 \quad$ (1), $2017 \quad$ 020057, http://doi.org/10.1063/1.5005390

[9] A. Hussain, E.O.C. Mkpojiogu, A.J. Isse, R.A. Mohammed. Grab mobile application: a usability evaluation. ICAST 2018, AIP Conf. Proc. 2018 020054, https://doi.org/10.1063/1.5055456

[10] A. Hussain, E.O.C. Mkpojiogu, A.M. Abduljabbar, A.H.G. Almadhagi. A usability evaluation of UUM mobile for students app on IOS and android platforms. ICAST 2018, AIP Conf. Proc. 2018 020052, https://doi.org/10.1063/1.5055454

[11] A. Hussain, E.O.C. Mkpojiogu, F. Hassan. Dimensions and sub-dimensions for the evaluation of m-learning apps for children: A review. International Journal of Engineering \& Technology (IJET), 7(3.20) 2018 291-295.

[12] A. Hussain, E.O.C. Mkpojiogu, M. Kutar. The impact of software features' perceived importance on the perceived performance of software products' quality elements. Journal of Computational and Theoretical Nanoscience. 16(56) $20192135-2140$.

[13] M. Certicky, M. Certicky, P. Sincak, G. Magyar, J. Vascak, F. Cavallo. Psychological indicators for modeling user experience in interactive digital entertainment. Sensor, 192019989.

[14] R. Akula, I. Garibay. VizTract: visualization of complex social networks for easy user perception. Big Data and Cognitive Computing, 3201917.

[15] J.G. Lee, K. Lee, S.H. Ryu. Vehicle politeness in driving situations. Future Internet, 11201948.

[16] Y. Chen, Z. Qian, W. Lei. Designing a situational awareness information display: Adopting an affordance-based framework to amplify user experience in environmental interaction design. Informatics, 320166.

[17] A. Gunay, C. Erbug. Eliciting positive user experience with self-service kiosks: pursuing 
possibilities. Behavior \& Information Technology, 342015 81-93

[18] M. Roussou, A. Katifori. Flow, staging, way funding, personalization: evaluating user experience with mobile museum narratives. Multimodal Technologies and Interaction, 2201832.

[19] G. Burger, J. Guna, M. Pogacnik. Suitability of inexpensive eye-tracking device for user experience in environmental interaction design. Informatics, 3 20186.

[20] Subramani, Prabu, K. Srinivas, R. Sujatha, and B. D. Parameshachari. "Prediction of muscular paralysis disease based on hybrid feature extraction with machine learning technique for COVID-19 and post-COVID-19 patients." Personal and Ubiquitous Computing (2021): 1-14.

[21] Bhuvaneswary, N., S. Prabu, K. Tamilselvan, and K. G. Parthiban. "Efficient Implementation of Multiply Accumulate Operation Unit Using an Interlaced Partition Multiplier." Journal of Computational and Theoretical Nanoscience 18, no. 4 (2021): 13211326.

[22] Hu, Liwen, Ngoc-Tu Nguyen, Wenjin Tao, Ming C. Leu, Xiaoqing Frank Liu, Md Rakib Shahriar, and SM Nahian Al Sunny. "Modeling of cloud-based digital twins for smart manufacturing with MT connect." Procedia manufacturing 26 (2018): 11931203.

[23] Seyhan, Kübra, Tu N. Nguyen, Sedat Akleylek, Korhan Cengiz, and SK Hafizul Islam. "Bi-GISIS KE: Modified key exchange protocol with reusable keys for IoT security." Journal of Information Security and Applications 58 (2021): 102788.

[24] Nguyen, Tu N., Bing-Hong Liu, Nam P. Nguyen, and Jung-Te Chou. "Cyber security of smart grid: attacks and defenses." In ICC 2020-2020 IEEE International Conference on Communications (ICC), pp. 1-6. IEEE, 2020.

[25] Z. Guo, K. Yu, Y. Li, G. Srivastava, and J. C. -W. Lin, "Deep Learning-Embedded Social Internet of Things for Ambiguity-Aware Social Recommendations", IEEE Transactions on Network Science and Engineering, doi: 10.1109/TNSE.2021.3049262.

[26] K. Yu, L. Tan, M. Aloqaily, H. Yang, and Y. Jararweh, "Blockchain-Enhanced Data Sharing with Traceable and Direct Revocation in IIoT", IEEE Transactions on Industrial Informatics, doi: 10.1109/TII.2021.3049141.

[27] K. Yu, L. Lin, M. Alazab, L. Tan, B. Gu, “Deep Learning-Based Traffic Safety Solution for a Mixture of Autonomous and Manual Vehicles in a 5G-Enabled Intelligent Transportation System", IEEE Transactions on Intelligent Transportation Systems, doi: 10.1109/TITS.2020.3042504
[28] R.G. Aghaei. Multimodal Software for Affective Education: User Interaction Design and Evaluation. Doctoral Thesis. Carleton University, 2017.

[29] Rajendrakumar, Shiny, and V. K. Parvati. "Automation of irrigation system through embedded computing technology." In Proceedings of the 3rd International Conference on Cryptography, Security and Privacy, pp. 289-293. 2019.

[30] L. Zhen, A. K. Bashir, K. Yu, Y. D. Al-Otaibi, C. H. Foh, and P. Xiao, "Energy-Efficient Random Access for LEO Satellite-Assisted 6G Internet of Remote Things", IEEE Internet of Things Journal, doi: 10.1109/JIOT.2020.3030856.

[31] L. Zhen, Y. Zhang, K. Yu, N. Kumar, A. Barnawi and Y. Xie, "Early Collision Detection for Massive Random Access in Satellite-Based Internet of Things," IEEE Transactions on Vehicular Technology, vol. 70, no. 5, pp. 5184-5189, May 2021, doi: 10.1109/TVT.2021.3076015.

[32] L. Tan, K. Yu, A. K. Bashir, X. Cheng, F. Ming, L. Zhao, X. Zhou, "Towards Real-time and Efficient Cardiovascular Monitoring for COVID-19 Patients by 5G-Enabled Wearable Medical Devices: A Deep Learning Approach", Neural Computing and Applications, 2021, https://doi.org/10.1007/s00521 021-06219-9

[33] Kumar, M. Keerthi, B. D. Parameshachari, S. Prabu, and Silvia liberata Ullo. "Comparative Analysis to Identify Efficient Technique for Interfacing BCI System." In IOP Conference Series: Materials Science and Engineering, vol. 925, no. 1, p. 012062. IOP Publishing, 2020.

[34] Subramani, Prabu, K. Srinivas, R. Sujatha, and B. D Parameshachari. "Prediction of muscular paralysis disease based on hybrid feature extraction with machine learning technique for COVID-19 and post-COVID-19 patients." Personal and Ubiquitous Computing (2021): 1-14.

[35]R.M. Ryan, E.L. Deci. Self-Determination Theory: Basic Psychological Needs in Motivation, Development, and Wellness. 2017, New York: Guilford Publishing

[36] J. Hemabala, E.S.M. Suresh. The frame work design of mobile learning management system. International Journal of Computer and Information Technology, 1(2) 2012 179-184.

[37] L. Senol, H. Gecili, P.O. Durdu. Usability evaluation of a Moodle based learning management system. EdMedia 2014, Tampere, Finland, June 23-26, 2014.

[38] M.M. Althobaiti, P. Mayhew. How usable are the learning management systems? The users have their say. EAI Endorsed Transactions on E-Learning, 3(11) 2016 1-9. 
[39] W.J.A.M. Lasanthika, W.D.N.S.M. Tennakoon. Assessing the adoption of learning management systems in higher education. GATR Global Journal of Business and Social Science Review, 7(3) 2019 204-208.

[40] M.P. Guimaraes, B. Alves, V.F. Martins, L.S.S Baglie, J.R. Brega, D.C. Dias. Embedded augmented reality applications into learning management systems. Lecture Notes in Computer Science, 2017.

[41] A. Gorbunovs, Z. Timsans, B. Zuga, V. Zagorskis. Conceptual design of the new generation adaptive learning management system. International Journal of Engineering \&Technology, 7 (2.28) 2017 129133.

[42] A. Alexiou, M.C. Schippers. Digital game elements, user experience and learning: a conceptual framework. Educ. Int. Technol., 232018 25452567.

[43] A.M. Abdullahi, M. Makhtar, S. Safie. The pattern of assessing learning management system among students. Indonesian Journal of Electrical Engineering and Computer Science, 13(1) 2019 1521.

[44] S. Sackstein, E. Coleman, T.V. Ndobe. Lecturers' perceptions of learning management systems within a previously disadvantaged university, 2019. IGI Global. Doi: 10.4018/978-1-5225-7473-6.ch001.

[45] R. Medina-Flores, R. Morales-Gamboa. Usability evaluation by experts of a learning management system. IEEE Revista Iberoamerica de Technologias del Apredizaje, 10(4) 2015 197-203.

[46] T. Dingler. Cognitive-aware systems to support information intake and learning. PhD Thesis. Institut fur Visualisierung und Interative Systeme der Universitat Stuttgart, 2016.

[47] C.C. Chigozie-Okwum, P.C. Ezeanyeji, J.N. Odii. Adoption of learning management systems in Nigerian tertiary institutions: issues and challenges. International Journal of Computer Applications, 181(3) 2018 5-10.

[48] D. Turnbull, R. Chugh, J. Luck. Learning management systems: an overview. In A. Tatnall (Ed.), Encyclopedia of Education and Information Technologies, 2019 1-7.

[49] V. Sonmez. Association of cognitive, affective, psychomotor and intuitive domains in education, sonmez model. Universal Journal of Educational Research, 5(3) 2017 347-356.

[50] A. Ajumunisha, A. Begam, A. Tholappen. Psychomotor domain of Bloom's taxonomy in teacher education. Shanlax Int'l Journal of Edu., 6(3) 2018 11-14.
[51] A.V. Ertemel. The role of gamification in online learning management system. $7^{\text {th }}$ Int'l Conf. of Strategic Research on Social Science and Education (ICoSReSSE), 13-15 October 2017, Antalya, Turkey, 239-247

[52] C. Sailer, J. Schito, P. Kiefer, M. Raubal. Teachers matter: challenges of using a location-based mobile learning platform, $2015 . \quad$ Doi: 10.13140/RG.2.1.1403.9767

[53] Z.A. Green, S. Batool. Emotionalized learning experiences: tapping into the affective domain. Evaluation and Program Planning, 622017 35-48.

[54] I. Aheisibwe, I. Kobusigye, J. Tayebwa. Bridging educational gap in higher institutions of learning using Bloom's taxonomy of educational objectives. African Educational Research Journal, 9(1) 2021 69-74.

[55] E. Pedroli, L. Greci, D. Colombo, S. Serino, P. Cipresso, S. Arlati, M. Mondellini, L. Boilini, V. Giussani, K. Gonlene, M. Agostoni, M. Sacco, M. Stramba-Badiale, G. Riva, A. Gaggioli. Characteristics, usability, and user experience of a system combining cognitive and physical therapy in a virtual environment: positive bike. Sensor, 18, 20182343.

[56] A. Dirin, T. Laine. User experience in mobile augmented reality: emotions, challenges, opportunities and best practices. Computers, 7 201833.

[57] S.C. Necula, V.D. Pavaloaia, C. Strimbei, O. Dospinescu. Enhancement of e-commerce websites with semantic web technologies. Sustainability, 10 20181955

[58] M. Luo, S. Zhang, Y. Zhang. Designing and implementation of efficient user interface in a synchronous e-learning system. $8^{\text {th }}$ International Conference on Information Technology in Medicine and Education (ITME), IEEE, 2016.

[59] M. Minge, M. Thuring. Hedonic and pragmatic halo effects at early stages of user experience. International Journal of Human-Computer Studies, 1092018 13-25.

[60] A. Janson, M. Sollner, J.M. Leimeister. Individual approximation of learning management systems - antecedents and consequences. AIS Transactions on Human-Computer Interaction, 9(3) 2017 173-201.

[61] A. Hussain, P. Shamala, E.O.C. Mkpojiogu. The effect of software features' perceived importance on the observed performance of software product qualities. Journal of Advanced Research in Dynamical and Control Systems (JARDCS), 11(08SI) 2019 1076-1082. 
[62] E.O.C. Mkpojiogu, N.L. Hashim. Improving the quality of requirements work products using scoring rubrics-assisted reading. Proceedings of the $6^{\text {th }}$ International Conference on Computing and Informatics 2017 (ICOCI'17), 25-27 April, 2017, Kuala Lumpur, Malaysia

[63] E.O.C. Mkpojiogu, A. Hussain, F. Hassan. A systematic review of usability quality attributes for the evaluation of mobile learning applications for children. ICAST 2018, AIP Conf. Proc. 6, https://doi.org/10.1063/1.5055494

[64] E.O.C. Mkpojiogu, N.L. Hashim, A. Hussain, K.L. Tan. The impact of user demographics on the perceived satisfaction and comfort of use of $\mathrm{m}$ banking apps. International Journal of Innovative Technology and Exploring Engineering, 8(8S) 2019 460-466.

[65] E.O.C. Mkpojiogu, O.E. Okeke-Uzodike, E.I. Emmanuel. Quality attributes for an LMS cognitive model for user experience design and evaluation of learning management systems. ICIIC 2021

[66] B.S. Bloom. Taxonomy of Educational Objectives: Handbook I: Cognitive Domain, 1956. New York: McKay.

[67] A. Mehrabian, J.A. Russell. An Approach to Environmental Psychology, 1974, MA, Cambridge: MIT Press.

[68] J. Hatami. Smart View: a study on students' attitude toward employing smart glasses as a medium of elearning. Master Thesis. Department of Informatics, Umea University, 2016. 